\title{
Kisspeptin-10 inhibits OHSS by suppressing VEGF secretion
}

\author{
Junyu Zhai ${ }^{1,2}$, Jiansheng Liu' ${ }^{1,2}$, Shigang Zhao ${ }^{3}$, Han Zhao ${ }^{3}$, Zi-Jiang Chen ${ }^{1,2,3}$, Yanzhi Du ${ }^{1,2}$ \\ and Weiping $\mathrm{Li}^{1,2}$
}

${ }^{1}$ Center for Reproductive Medicine, Ren Ji Hospital, School of Medicine, Shanghai Jiao Tong University, Shanghai, China, ${ }^{2}$ Shanghai Key Laboratory for Assisted Reproduction and Reproductive Genetics, Shanghai, China and ${ }^{3}$ National Research Center for Assisted Reproductive Technology and Reproductive Genetics, The Key Laboratory for Reproductive Endocrinology of Ministry of Education, Shandong Provincial Key Laboratory of Reproductive Medicine, Center for Reproductive Medicine, Shandong Provincial Hospital, Shandong University, Jinan, China

Correspondence should be addressed to Y Du or W Li; Email: yanzhidu@hotmail.com

\begin{abstract}
The aim of the present study was to elucidate the effects of kisspeptin-10 (Kp-10) on ovarian hyperstimulation syndrome (OHSS) and its related mechanism in OHSS rat models, human umbilical vein endothelial cells (HUVECs) and human luteinized granulosa cells. OHSS is a systemic disorder with high vascular permeability (VP) and ovarian enlargement. KISS1R (KISS1 receptor) is the specific receptor of kisspeptin. The kisspeptin/KISS1R system inhibits the expression of vascular endothelial growth factor (VEGF), which is the main regulator of VP. In our study, decreased expression of Kiss1r was observed in both ovaries and lung tissue of OHSS rats. Injection of exogenous Kp-10 inhibited the increase of VP and VEGF while promoting the expression of Kiss1 $\mathrm{r}$ in both the ovarian and lung tissue of OHSS rats. Using HUVECs, we revealed that a high level of 17- $\beta$ estradiol $\left(E_{2}\right)$, a feature of OHSS, suppressed the expression of KISS1R and increased VEGF and nitric oxide (NO) through estrogen receptors (ESR2). Furthermore, KISS1R mRNA also decreased in the luteinized human granulosa cells of high-risk OHSS patients, and was consistent with the results in rat models and HUVECs. In conclusion, Kp-10 prevents the increased VP of OHSS by the activation of KISS1R and the inhibition of VEGF.

Reproduction (2017) 154 355-362
\end{abstract}

\section{Introduction}

Ovarian hyperstimulation syndrome (OHSS) is an iatrogenic, serious and potentially fatal complication of ovarian stimulation. It contains a broad spectrum of clinical manifestations including massive ovarian enlargement, high level of 17- $\beta$ estradiol $\left(E_{2}\right)$, high vascular permeability (VP), ascites, pleural effusion, reduced renal perfusion, thrombotic complications and possibly death (Delvigne \& Rozenberg 2002, GarciaVelasco \& Pellicer 2003). Mild OHSS occurs in 32\% of IVF cycles while 10-15\% of IVF patients develop moderate OHSS and $5-8 \%$ of the patients are diagnosed with severe OHSS (Humaidan et al. 2010, Toftager et al. 2016). Despite being a potentially life-threatening condition, the pathogenesis of OHSS is still unclear due to its elusive pathophysiology.

The symptoms of OHSS are due to high VP, and the most important mediator is vascular endothelium growth factor (VEGF). VEGF makes local capillaries leaky by binding to and phosphorylating VEGF receptor 2 (VEGFR2) in endothelial cells (Gille et al. 2001). In addition, VEGF is a VP enhancer whose potency is 5000 times stronger than histamine and plays an important role in the incidence of OHSS (Yan et al. 1993,
Neulen et al. 1995, Wang et al. 2002). Thus, VEGF promotes OHSS onset by regulating nitric oxide (NO) and junction proteins and thereby increasing VP (Farkkila et al. 2011, Wang et al. 2015). Apart from being a powerful mediator of VP, VEGF also participates in the formation of the corpus luteum by mediating vascularization (Aboulghar \& Mansour 2003, Harada et al. 2010).

To date, discontinuing gonadotropin therapy (coasting) and reducing human chorionic gonadotropin (hCG) usage are common approaches in the prevention of OHSS. Some practitioners prescribe gonadotropin releasing hormone agonist $(\mathrm{GnRHa})$ instead of hCG for final oocyte maturation in order to prevent OHSS (Stadtmauer et al. 2011). However OHSS may still occur in the very high risk individual using GnRHa (Fatemi et al. 2014, Ling et al. 2014). Another common strategy used in clinics is embryo cryopreservation. Although it is useful for avoiding the late form of OHSS caused by endogenous hCG, embryo cryopreservation cannot prevent early OHSS development caused by exogenous hCG administration (Braat et al. 2010, Naredi et al. 2014). Therefore OHSS is a potentially lethal condition with an unclear mechanism and it is necessary for us to investigate the new mechanisms involved in mediating OHSS. 
Kisspeptin (Kp) is a polypeptide encoded by the KISS1 gene and its specific receptor is KISS1R (KISS1 receptor) (Muir et al. 2001). The Kp precursor contains 145 amino acids and can be hydrolyzed into Kp-54, $\mathrm{Kp}-14, \mathrm{Kp}-13$ and Kp-10. Kp-10, the shortest subtype with high activity, plays a vital role in many tissues. The Kp/KISS1R system participates in the female reproductive endocrine system by directly regulating each part of the hypothalamo-pituitary-ovarian axis (HPOA) (Novaira et al. 2009, Millar \& Newton 2013). Kisspeptin is the GnRH secretagogue and exogenously administered kisspeptin could induce a dose-dependent release of luteinizing hormone $(\mathrm{LH})$ and follicle stimulating hormone ( $\mathrm{FSH}$ ) from the anterior pituitary. In addition, Kp and KISS1R are expressed in the ovaries, where $\mathrm{Kp}$ is involved in ovarian follicular development and participates in progesterone regulation without affecting $\mathrm{E}_{2}$ production (Peng et al. 2013, Jayasena et al. 2014, Fernandois et al. 2016). Kp-10 inhibits VEGF expression in human umbilical vein endothelial cells (HUVECs) through KISS1R, while VEGF is an important mediator of OHSS onset (Cho et al. 2009). Moreover, $\mathrm{Kp}-54$, another member of the Kp family, can be used effectively and safely to trigger oocyte maturation for IVF patients at a high risk of OHSS (Abbara et al. 2015). Thus, we suggested that Kp/KISS1R system could prevent OHSS by inhibiting VEGF.

High level of $E_{2}$ is another characteristic of OHSS, which is closely related to the number of follicles and accounts for the increase of serum VEGF and VP to a large extent. $E_{2}$ promotes the expression of VEGF in several cells, depending on the presence of ESR1 (Bogin \& Degani 2002, Garvin et al. 2006). Thus, $E_{2}$ is not only a predictor but also a regulator of OHSS onset. Serum $\mathrm{E}_{2}$ plays an indispensable role in OHSS onset, and some $E_{2}$ inhibition drugs such as letrozole have been used in clinic to induce ovulation as well as prevent OHSS (He et al. 2014, Sahin et al. 2016). Moreover, the KISS1R promoter contains an estrogen response element (ERE), the binding site of estrogen receptors, which may play a negative role in KISS $1 R$ transcription in pituitary cells (DeFino et al. 2010a). Thus, the Kp/KISS1R system may be regulated by $E_{2}$ and may participate in the pathogenesis of OHSS. Therefore our study investigated the function of Kp/KISS1R system in OHSS prevention and the regulation of high $E_{2}$ to Kp/KISS1R system.

\section{Materials and methods}

\section{Animal models}

A total of 18 immature 22-day-old female Wistar rats were fed ad libitum with a 12-h light and 12-h darkness schedule. The rats were randomly divided into three groups: OHSS group, the OHSS + Kp-10 group and the control group. In the OHSS group, rats were subcutaneously injected with 10IU PMSG (PROSPEC, East Brunswick, USA) for 4 consecutive days to promote follicular development. They were then given $30 \mathrm{IU}$ hCG (s.c.) (Livzon Group, Guangdong, China) on the fifth day (Ferrero et al. 2014). In the OHSS +Kp-10 group, the management was same as the OHSS group except that the animals were given $30 \mathrm{IU}$ hCG and $40 \mathrm{nmol} \mathrm{Kp}-10$ (intravenous) (GenScript, Nanjing, China) together on day 5. In the control group, the 24-day-old rats were pretreated with 10 IU PMSG. Two days later, $10 \mathrm{IU}$ hCG was injected into the control group to mimic a routine ovarian stimulation (Ferrero et al. 2014).

All the rats were killed by decapitation after hCG administration for $48 \mathrm{~h}$.

Protocols for animal handling were performed in accordance with UK legal requirements and approved by the animal ethics committee of Ren Ji Hospital, School of Medicine, Shanghai Jiao Tong University.

\section{OHSS indicators measurement}

\section{VP detection}

All the rats were anesthetized by pentobarbital $48 \mathrm{~h}$ after hCG injection. First, $0.2 \mathrm{~mL}$ methylene blue was injected into the caudal vein of the rats, and the peritoneal cavity was filled with $5 \mathrm{~mL} 0.9 \%$ saline $30 \mathrm{~min}$ after methylene blue injection. After the rats were massaged for $30 \mathrm{~s}$, the fluid was extracted from the peritoneal cavity and centrifuged. The methylene blue concentration highlighting the abdominal vascular permeability (VP) was measured at $600 \mathrm{~nm}$ by microplate spectrophotometer (Ferrero et al. 2014).

\section{Sample collection and processing}

The whole blood was collected from the orbit before hCG administration and the ovaries were removed and weighted immediately after the rats were killed. The ovaries and serum were stored at $-80^{\circ} \mathrm{C}$ for further experiments.

\section{Patients and subjects}

Patients with high level of $E_{2}$ (serum $E_{2}$ level higher than $6000 \mathrm{pg} / \mathrm{mL}$ on the day of hCG administration) or with more than 25 dominant follicles were identified as being at high risk of OHSS in IVF cycles. Follicles whose diameter was larger than $1.4 \mathrm{~cm}$ on the ovum retrieval day during IVF cycles were identified as dominant follicles. Human granulosa-lutein cells were recovered from the follicular fluid as described previously (Iwase et al. 2009) from the Center for Reproductive Medicine, Ren Ji Hospital, School of Medicine, Shanghai Jiao Tong University. The granulosa cells were purified with FicollPaque (GE-HealthCare Bio-Science, Uppsala, Sweden) and stored at $-80^{\circ} \mathrm{C}$. Cases with a low level of $E_{2}(<4000 \mathrm{pg} / \mathrm{mL})$ and fewer dominant follicles $(<15)$ in IVF cycles were chosen as the control group. Age, BMI, protocol and hormonal status were matched, and endocrine diseases such as primary ovarian insufficiency (POI) and polycystic ovary syndrome (PCOS) were excluded. The menstrual cycles of all patients are within 26-32 days. 
All procedures were reviewed and approved by the Institutional Review Board of Ren Ji Hospital, School of Medicine, Shanghai Jiao Tong University.

\section{$E_{2}$ concentration measurement}

The $E_{2}$ concentration of rat serum before hCG administration was detected using an Estradiol ELISA Kit (Cayman Chemical).

\section{Total RNA extraction and quantitative real-time PCR}

The total RNA of cells and tissues was extracted using an animal total RNA isolation kit (FOREGENE, Chengdu, China), and was then reverse transcripted into cDNA (TAKARA). The expression of the selected genes including VEGF, KISS1R, KISS1, VE-cadherin, ESR2 and $\beta$-ACTIN was estimated by quantitative real-time PCR (qRT-PCR) using SYBR (Toyobo, Osaka, Japan). The expression of these genes was normalized to the housekeeping gene $\beta$-ACTIN using $\Delta \Delta \mathrm{Ct}$ method. The sequences for the primers of target genes are presented in Table 1.

\section{Western blot}

$30 \mu \mathrm{g}$ protein from tissue or cells lysed with a RIPA buffer was loaded onto $8-10 \%$ SDS gel coupled with loading buffer, transferred to a nitrocellulose (NC) membrane. The nonspecific binding sites were then blocked using 5\% non-fat dry milk and incubated with diluted anti-VEGF antibody (Santa Cruz Biotechnology) (1:200), anti-KISS1R antibody (Santa Cruz Biotechnology) (1:200), anti-ESR1 antibody (Cell Signaling) (1:1000) and anti-ESR2 antibody (Sigma, Chemical) (1:200) at $4{ }^{\circ} \mathrm{C}$ for overnight. This step was followed by incubation for $1.5 \mathrm{~h}$ with diluted peroxidase-conjugated secondary antibodies at room temperature. Finally, the protein signals were detected using ECL Western blotting substrate, and the bands obtained were quantified by densitometry and normalized to the GAPDH.

\section{Cell culture}

HUVECs were maintained in DMEM/F-12 medium (Gibco), containing 10\% fetal bovine serum (Gibco) and 1\% PenicillinStreptomycin-Neomycin (Gibco). The cultures were incubated

Table 1 Sequences for the primers of target genes in the real-time PCR.

\begin{tabular}{ll}
\hline Genes & Sequence of primers \\
\hline KISS1R & Forward: 5'-ATCTACGTCATCTGCCGCCAC-3' \\
& Reverse: 5'-TCACGTACCAGCGGTCCACAC-3' \\
$\beta$-Actin & Forward: 5'-GGGAAATCGTGCGTGACATTAAG-3' \\
& Reverse: 5'-TGTGTTGGCGTACAGGTCTTTG-3' \\
$V E G F$ & Forward: 5'-TCACCAAGGCCAGCACATAG-3' \\
KISS1 & Reverse: 5'-TTAACTCAAGCTGCCTCGCC-3' \\
& Forward: 5'-TGAACTCACTGGTTTCTTGGC-3' \\
VE-Cadherin & Reverse: 5'-CGAAGGAGTTCCAGTTGTAGT-3' \\
& Forward: 5'-GCGACTACCAGGACGCTTTCA-3' \\
ESR2 & Reverse: 5'-CATGTATCGGAGGTCGATGGTG-3' \\
& Forward: 5'-GCAGACCACAAGCCCAAATG-3' \\
& Reverse: 5'-AGCGATCTTGCTTCACACCA-3' \\
\hline
\end{tabular}

at $37^{\circ} \mathrm{C}$ in a humidified atmosphere with $5 \% \mathrm{CO}_{2}$. Cells were passaged every 3 days to obtain exponential growth.

\section{Small interfering (si) RNA knocking down}

$2 \times 10^{5}$ HUVECs were seeded on six-well plates for $24 \mathrm{~h}$. The culture medium was changed and a mixture of siRNA (50 pmol) and RNAiMAX (Invitrogen) $(9 \mu \mathrm{L})$ in OPTI-MEM $(250 \mu \mathrm{L})$ was added into each well. Cells were further cultivated for $48 \mathrm{~h}$ before being treated with $\mathrm{E}_{2}$ (Sigma, Chemical) $(5000 \mathrm{pg} / \mathrm{mL})$ for $24 \mathrm{~h}$. The specific sequences targeting ESR2 were as follows:

\section{ESR2 siRNA, sense, 5'-CCAGCCAUGACAUUCUA}

UATT-3,

anti-sense, 5'-UAUAGAAUGUCAUGGCUGGTT-3. Scrambled siRNA (NC), sense, 5'-UUCUCCGAACGU GUCACGUTT-3, anti-sense, 5'-ACGUGACACGUUCGGAGAATT-3.

\section{NO concentration measurement}

HUVECs were lysed using a cell and tissue lysis buffer (Beyotime, Jiangsu, China) for NO assay and then the NO concentration of lysate was detected using a Griess Reagent Kit (Beyotime).

\section{Statistical analysis}

Results were expressed as the mean value \pm standard deviation (S.D.). The differences between the experimental and the control groups were analyzed using a one-way ANOVA and unpaired Student's $t$ test. Significance was defined as $P<0.05$. All analyses were conducted using SPSS 21.0 for Windows (IBM).

\section{Results}

\section{Reduced expression of Kiss1r was observed in OHSS rats while Kp-10 injection inhibited the increase of VP and VEGF of OHSS rats by Kiss1r activation}

In order to investigate the relationship between Kp/Kiss1 r system and OHSS onset, we built OHSS rat models at first. The significantly higher ovarian weight, abdominal VP, serum $E_{2}$ concentration and VEGF abundance in ovaries and lung tissue of the OHSS group (Fig. 1A, B, $\mathrm{C}$ and D) demonstrated that our OHSS models were successful. Lung tissue consists of numerous capillaries and venules, which play a vital role in the regulation of VP. The expression of Kiss1 $r$ significantly decreased both in ovaries and lung tissue of OHSS rats (Fig. 1E) without affecting ovarian kiss 1 mRNA (data not shown).

Exogenous $\mathrm{Kp}-10$ was then injected into OHSS rats to verify the effect of $\mathrm{Kp} / \mathrm{Kiss} 1 \mathrm{r}$ system on OHSS onset. The exogenous Kp-10 injection inhibited the increase of abdominal VP of the OHSS group almost to the level of the control group (Fig. 1F). Meanwhile, Kp-10 also 

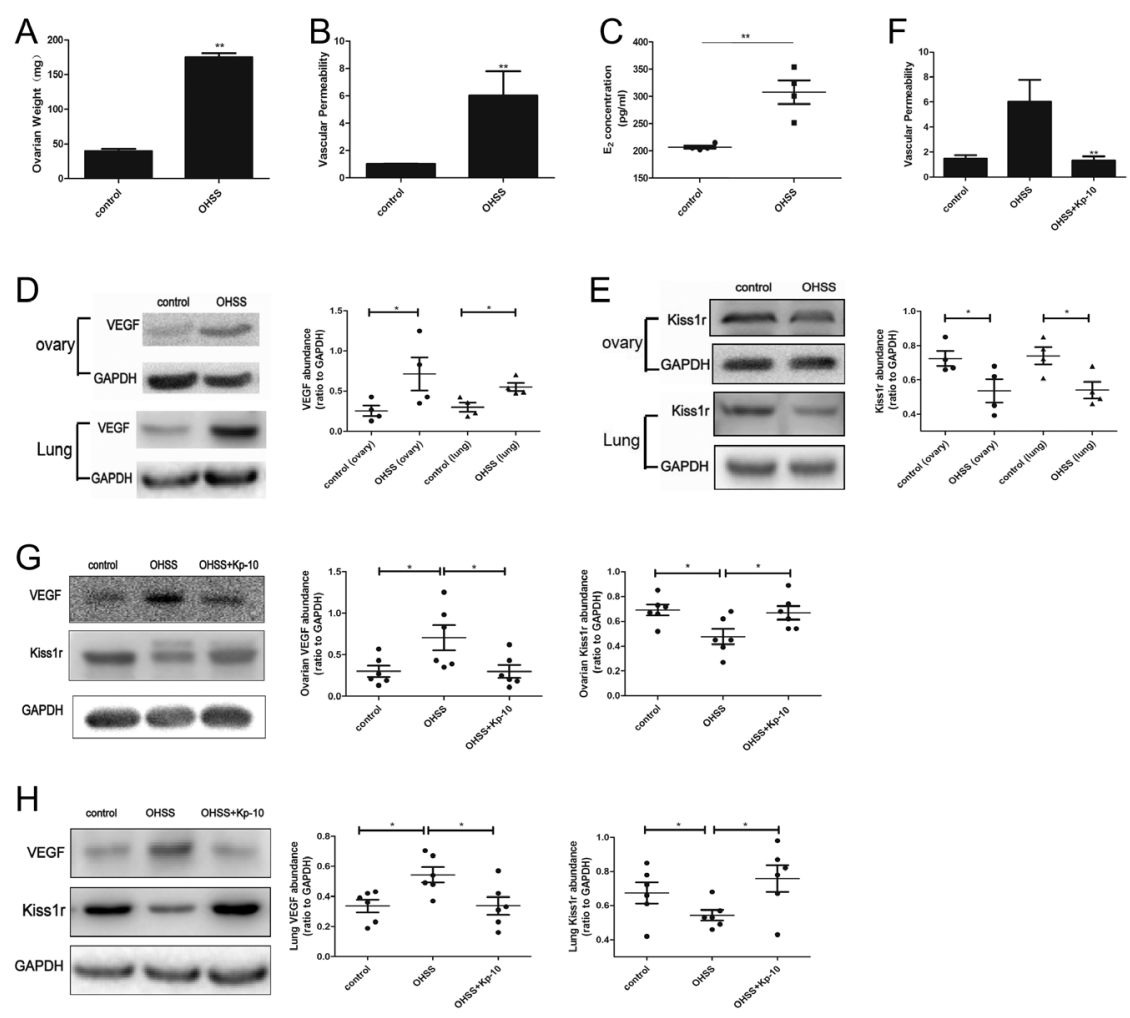

significantly enhanced the expression of Kiss1 $\mathrm{r}$ as well as inhibited VEGF in the ovaries (Fig. 1G) and lung tissue (Fig. 1H) of OHSS models. Thus, Kp/Kiss1r system has an effect on OHSS prevention by inhibiting VEGF expression.

\section{High level of $E_{2}$ suppressed KISS1R and increased VEGF in HUVECs}

OHSS is a systemic disorder with high VP and high VEGF expression while vascular endothelial cells are mainly responsible for the regulation of VP with high expression of VEGF (Kang et al. 2016). Thus, HUVECs were chosen as the in vitro cell line. Furthermore, a high level of $\mathrm{E}_{2}$ is a characteristic of OHSS and $\mathrm{E}_{2}$ may play a negative role in the expression of KISS1R in previous studies (DeFino et al. 2010a). Thus, HUVECs were treated with $E_{2}$ to investigate the mechanism underlying the decreased KISS1R in OHSS. Treatment of HUVECs with high $\mathrm{E}_{2}$ for $48 \mathrm{~h}$ reduced KISS1R $\mathrm{mRNA}$ and protein levels in a concentration-independent manner (Fig. 2A). Meanwhile, high $\mathrm{E}_{2}(>5000 \mathrm{pg} / \mathrm{mL}$ ) also increased VEGF mRNA and NO synthesis $(t=-3.044$, $P=0.038$ ) (Fig. 2B and C) in HUVECs, which both represent the increase of VP. Therefore a high level of $E_{2}$ inhibited KISS1R and promoted the increase of VEGF and VP.

In addition, HUVECs were treated with both Kp-10 and $E_{2}$ to verify the effect of $K p-10$ on the promotion of $\mathrm{E}_{2}$ to VEGF. $\mathrm{E}_{2}$ promoted VEGF mRNA significantly in HUVECs while Kp-10 treatment inhibited the increase of VEGF induced by $E_{2}$ (Fig. 2D). This result was consistent with rat models and demonstrated that high $\mathrm{E}_{2}$ could $\mathrm{Kp} / \mathrm{KISS} 1 \mathrm{R}$ system. in KISS1
Figure 1 Reduced expression of KISS1R was observed in ovaries and lung tissue of OHSS rats while the increase of VP and VEGF was inhibited by exogenous $\mathrm{Kp}$-10 injection in OHSS rat models. (A, B, C and D) Ovarian weight, abdominal $\mathrm{VP}$, serum $\mathrm{E}_{2}$ concentration and VEGF expression of ovaries and lung tissue of the control and OHSS group. $n=4$. The left panel shows the representative images of Western blot assays while the right panel clarifies the protein levels of all animals. The OD value was used to represent the abdominal VP of rats and this figure shows the ratio of OHSS group to control group. (E) The expression of Kiss1 $r$ of the control and OHSS groups in both ovaries and lung tissue. $n=4$. (F) Abdominal VP of the control, OHSS and OHSS + Kp-10 group. $n=6$. (G) The expression of ovarian VEGF and Kiss1 $r$ in the control, OHSS and OHSS + Kp-10 groups. $n=6$. $(\mathrm{H})$ The expression of VEGF and Kiss1 $r$ in lung tissue of the control, OHSS and OHSS +Kp-10 groups. $n=6 .{ }^{*} P<0.05,{ }^{* *} P<0.01$. Western blots show the representative images.

promote the expression of VEGF partially by inhibiting

\section{$E_{2}$ suppressed KISS1R and increased VP in HUVECs through the activation of ESR2}

$E_{2}$ is activated when it combines with estrogen receptors (ERs), including ESR1 and ESR2. ESR1 is almost absent while ESR2 is present in HUVECs (Fig. 3A). Specific ESR2 siRNA was transferred into HUVECs, and ESR2 was reduced to less than $10 \%$ (Fig. 3B). The reduction of KISS1R after $E_{2}$ treatment was partially reversed both in mRNA and protein levels after ESR2 knockdown, which suggested that ESR2 participated in the negative regulation of $E_{2}$ to KISS1R (Fig. 3C). Furthermore, the expression of VEGF decreased both in mRNA and protein levels after ESR2 knockdown (Fig. 3D). The downstream factors of VEGF also changed with ESR2 reduction. VE-cadherin $\mathrm{mRNA}$ increased and $\mathrm{NO}$ was reduced significantly ( $t=7.39, P=0.002)$ (Fig. $3 \mathrm{E}$ and $\mathrm{F}$ ), which could mediate a decrease in VP. Thus, $E_{2}$ inhibited KISS1R and promoted VEGF through binding to ESR2, resulting in a high $\mathrm{VP}$.

KISS1R was reduced in the granulosa cells of patients at high risk of OHSS with no significant change observed

The expression of the Kp-10/KISS1R system was detected in clinic samples to verify the results in rat models and HUVECs. The granulosa cells of patients at high risk 


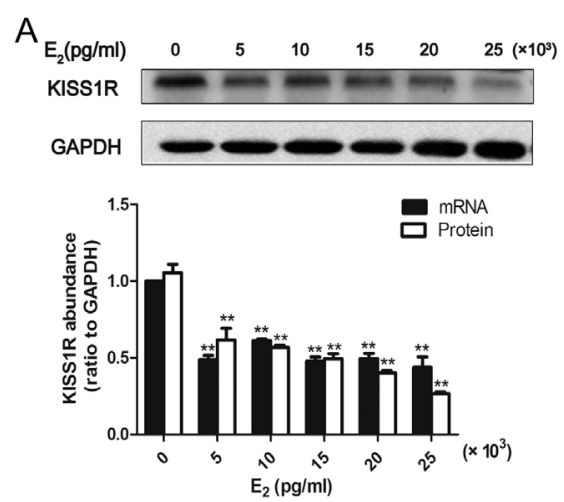

B
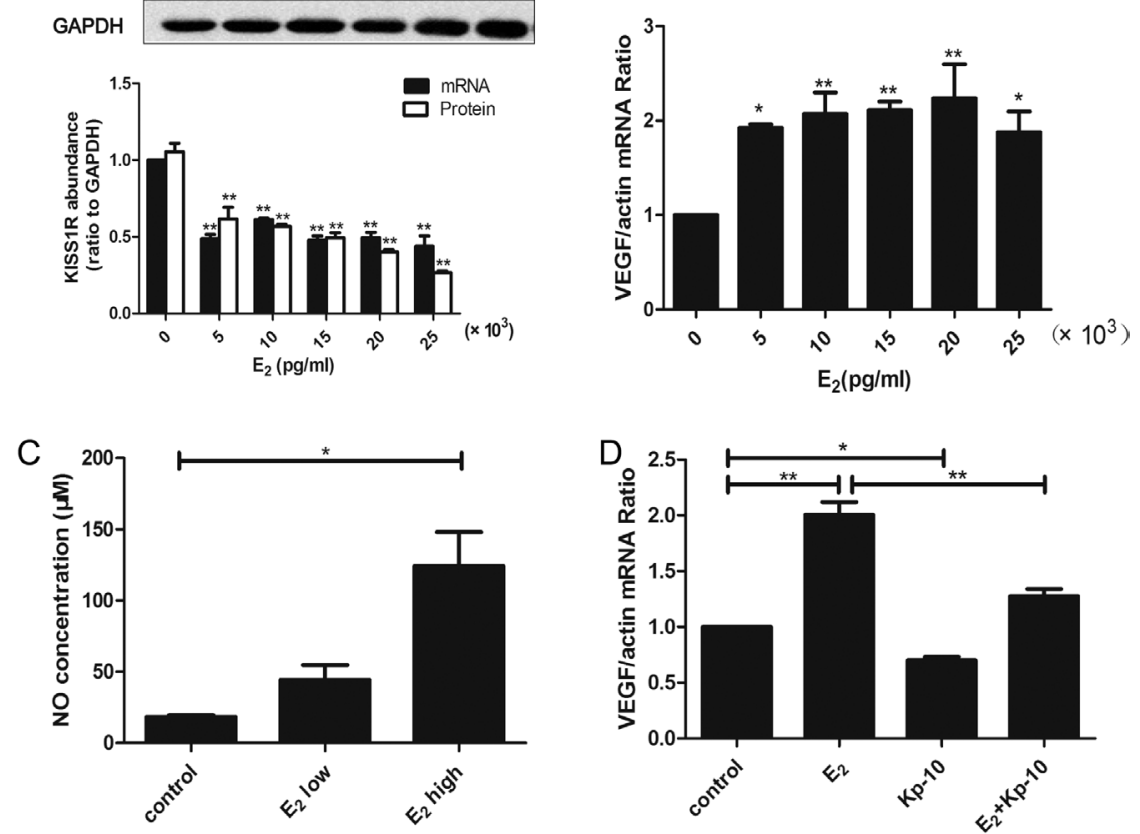

Figure $2 E_{2}$ inhibited KISS1R and promoted VP in HUVECs. (A) Expression of KISS1R mRNA and protein after treating with $\mathrm{E}_{2}(5000$, $10,000,15,000,20,000$ and $25,000 \mathrm{pg} / \mathrm{mL}$ ) for $48 \mathrm{~h}$ in HUVECs. (B) VEGF mRNA expression after treating with $\mathrm{E}_{2}$ for $24 \mathrm{~h}$ in HUVECs.

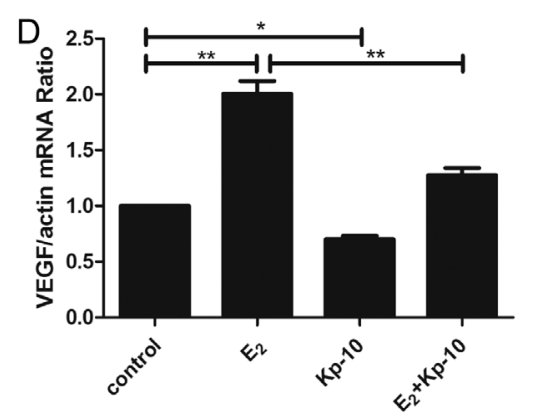
(C) NO concentration of HUVECs lysate after treating with $\mathrm{E}_{2}$ (low: $5000 \mathrm{pg} / \mathrm{mL}$, high: $10,000 \mathrm{pg} / \mathrm{mL}$ ) for $24 \mathrm{~h}$. Control: $18.48 \pm 1.57 \mu \mathrm{M}, \mathrm{E}_{2}$ low: $44.4 \pm 14.6 \mu \mathrm{M}, \mathrm{E}_{2}$ high: $124.3 \pm 33.4 \mu \mathrm{M}$. (D) VEGF mRNA level of HUVECs after treating with $E_{2}(5000 \mathrm{pg} / \mathrm{mL})$, $\mathrm{Kp}-10(10 \mu \mathrm{M})$, both $E_{2}$ and $\mathrm{Kp}-10$. In the $E_{2}+K p-10$ group, HUVECs were pretreated with $\mathrm{E}_{2}$ for $24 \mathrm{~h}$ and then $10 \mu \mathrm{M} \mathrm{Kp}-10$ for another $24 \mathrm{~h} . * P<0.05, * * P<0.01, n=3$ separate experiments. Western blots show the representative images.

of OHSS showed a significantly decreased expression of KISS1R mRNA ( $n=13)$ while no significant change was identified in KISS1 mRNA between the OHSS and control groups (Fig. 4A and B). The clinical information of patients is presented in Table 2. The results of clinic samples were consistent with rat models and HUVECs.

\section{Discussion}

The Kp/KISS1R system is an acknowledged VEGF inhibitor, and VEGF promotes the incidence of OHSS (MacLean et al. 2014, Golzar \& Javanmard 2015). Thus, we hypothesized that Kp/KISS1R system played a role in the pathogenesis of OHSS. In order to investigate the role of $\mathrm{Kp} / \mathrm{KISS} 1 \mathrm{R}$ in the incidence of OHSS, we measured the expression of Kp/KISS1R in ovaries and lung tissue of OHSS models, which were built according to an established method (Ferrero et al. 2014). The ovaries are the origin of OHSS onset, while lung tissue is abundant with vessels which are closely related to VP regulation and pleural effusion. Thus, the high VEGF and decreased Kiss1 $r$ both in ovaries and lung tissue had an effect on the pathogenesis of OHSS.

Kisspeptin polypeptide can be hydrolyzed into Kp-54, 14,13 and 10 . We chose Kp-10 instead of other subtypes to investigate the role of $\mathrm{Kp}$ in OHSS prevention because previous studies have indicated that Kp-10 inhibited the expression of VEGF in HUVECs, the main inducer of high VP. Moreover, Kp-10 also promotes follicle maturation, ovulation and progesterone production (Pineda et al. 2010, Sebert et al. 2010, Xiao et al. 2011, Ni et al. 2012). Exogenous Kp-10 injection decreased VP and VEGF by enhancing Kiss1 $\mathrm{r}$ in OHSS rats without affecting ovulation. Therefore Kp-10 injection is a promising approach to effectively and safely prevent OHSS. Kp-54 injection also induces egg maturation and reduces the incidence of OHSS in women at high risk (Abbara et al. 2015). Kp-54 is the primary fragment of kisspeptin also found circulating during human pregnancy. Therefore other subtypes of kisspeptin may also have effects on OHSS prevention, which will require further investigation.

Since decreased KISS1R was involved in OHSS onset, we further investigated the mechanism. Serum $E_{2}$ on the day of hCG administration is an important indicator of OHSS prediction (Papanikolaou et al. 2006, Delvigne 2009). Moreover, $E_{2}$ also inhibits the transcription of KISS1R in the pituitary cell line. Therefore we treated HUVECs with a high level of $E_{2}(>5000 \mathrm{pg} / \mathrm{mL})$ to investigate the relationship among $\mathrm{E}_{2}, \mathrm{KISS} 1 \mathrm{R}$ and OHSS onset. $E_{2}$ inhibited the expression of KISS1R and promoted VEGF and NO in HUVECs. Thus, a high level of $\mathrm{E}_{2}$ boosted OHSS by inhibiting KISS1R, which resulted in increased VEGF and high VP, inducing edema, ovarian enlargement and pleural effusion.

$E_{2}$ not only suppresses KISS1R in endothelial cells but also regulates the expression of KISS1 in the arcuate nucleus (ARC) by negative feedback (Smith et al. 2005). This is consistent with the hypothesis that high $\mathrm{E}_{2}$ inhibits the KISS1/KISS1R system to induce the incidence of OHSS. However it is contrary to the result demonstrating no significant change in ovarian KISS1 mRNA and serum kisspeptin concentration (data not shown) between the OHSS and control groups. Different organs react differently to high $E_{2}$ (Millar et al. 2010). Thus, $E_{2}$ might 


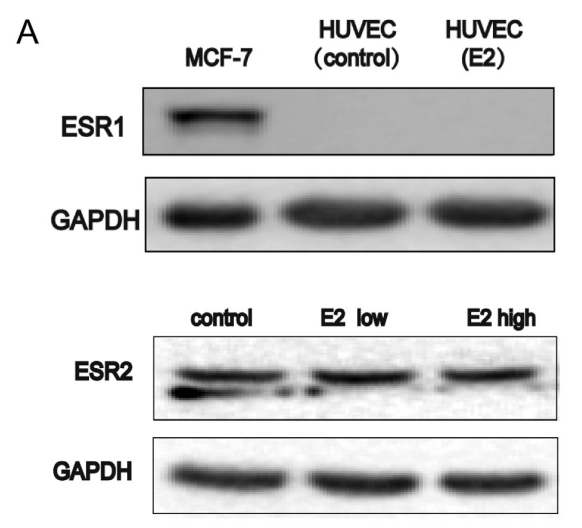

D

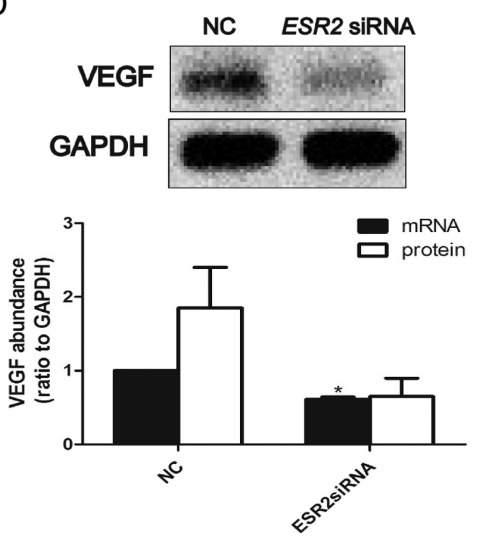

B
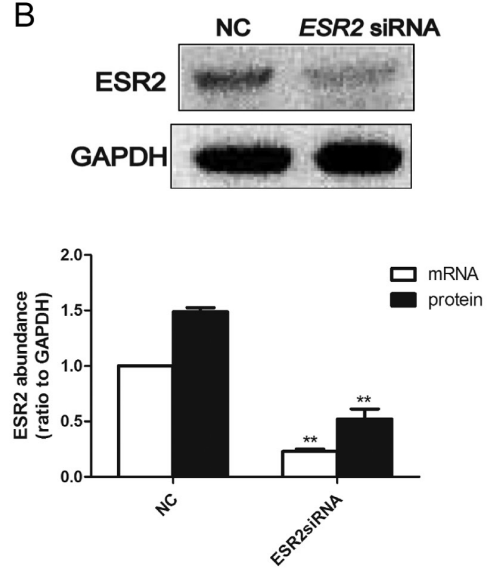

E

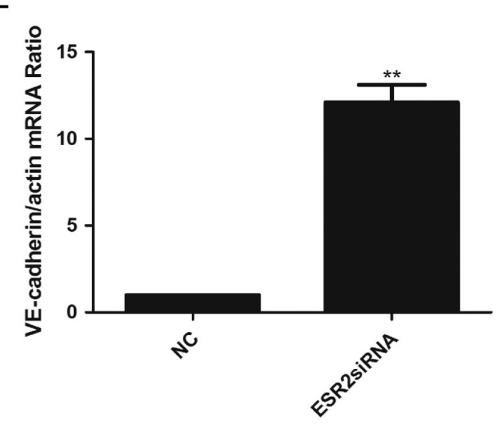

C
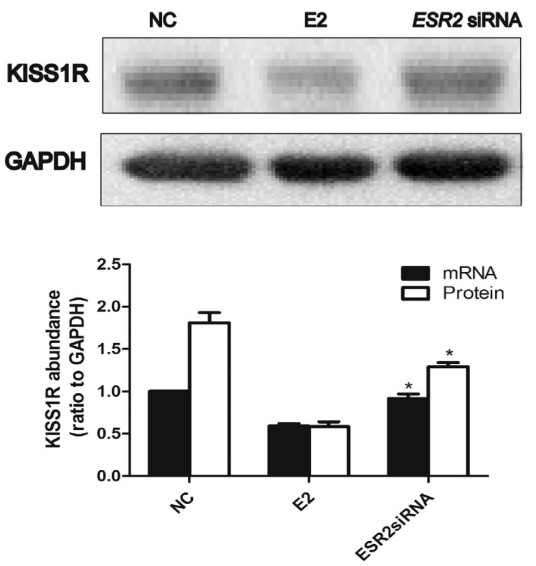

F

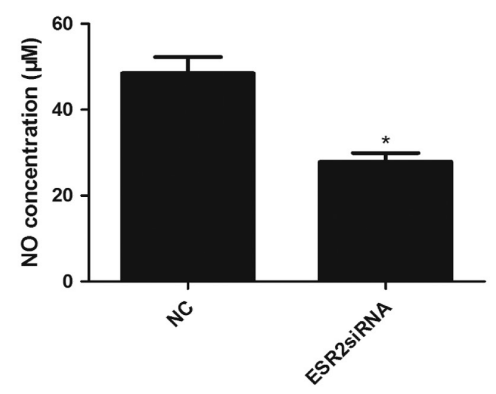

Figure $3 \mathrm{E}_{2}$ inhibited KISS1R and promoted VP through ESR2. (A) Expression of ESR1 and ESR2 protein in HUVECs ( $\mathrm{E}_{2}$ low: $5000 \mathrm{pg} / \mathrm{mL}, \mathrm{E}_{2}$ high: $10,000 \mathrm{pg} / \mathrm{mL}$ for $24 \mathrm{~h}$ ). (B) The efficiency of ESR2 knockdown in HUVECs in both mRNA and protein levels after ESR2 siRNA transfection for $48 \mathrm{~h}$. (C) KISS1R mRNA and protein expression of HUVECs after ESR2 knockdown. The gel picture is the presentative image of western blot. HUVECs were treated with $\mathrm{E}_{2}(5000 \mathrm{pg} / \mathrm{mL})$ for $24 \mathrm{~h}$ after ESR2 knockdown, and then the downstream factors were detected. (D) VEGF mRNA and protein levels after ESR2 knockdown in HUVECs. (E and F) VE-cadherin mRNA level and NO concentration of HUVECs after ESR2 knockdown. NO concentration: control group: $48.51 \pm 5.32 \mu \mathrm{M}, E S R 2$ siRNA group: $27.88 \pm 2.89 \mu \mathrm{M}$. ${ }^{*} P<0.05,{ }^{* *} P<0.01, n=3$ separate experiments. Western blots show the representative images.

have no effect on KISS1 expression of granulosa cells, or the positive and negative regulation of $E_{2}$ to ovarian KISS1 mRNA offset each other and resulted in a constant expression. Moreover, intra-ovarian $\mathrm{Kp}$ was also regulated throughout the cycle and a surge was detected before ovulation (Castellano et al. 2006). We chose the
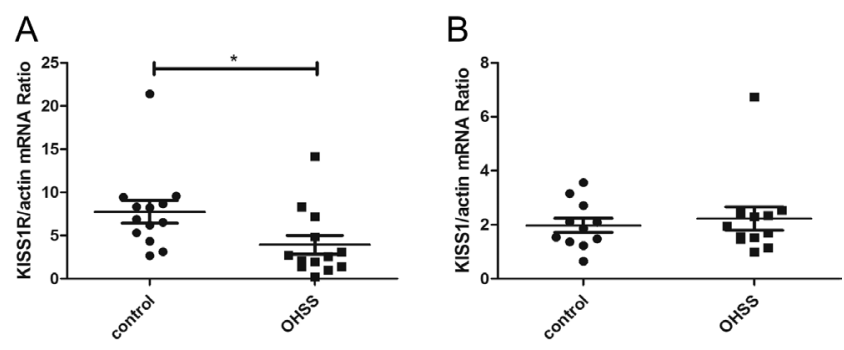

Figure 4 KISS1 and KISS1R expression in the granulosa cells of OHSS and control patients. (A) KISS1R mRNA expression in granulosa cells of patients at high risk of OHSS and control patients. $n=13$. (B) KISS1 mRNA expression of granulosa cells of patients at high risk of OHSS and control patients. $n=13 . * P<0.05$. granulosa cells of ovum retrieval day to remove the difference of Kp expression between various periods.

ESR1 and ESR2 are ligand-dependent transcription factors in target tissues and have strong affinity with $\mathrm{E}_{2}$ (Filardo \& Thomas 2005, Prossnitz \& Barton 2014). In addition, these two ERs are manifested in

Table 2 Clinical and biological characteristics of patients involved in the present study.

\begin{tabular}{lcc}
\hline & OHSS $(n=13)$ & Control $(n=13)$ \\
\hline Age & $29.69 \pm 3.06$ & $29 \pm 3.08$ \\
FSH $(\mathrm{IU} / \mathrm{L})$ & $6.84 \pm 1.08$ & $7.51 \pm 0.95$ \\
$\mathrm{LH}(\mathrm{IU} / \mathrm{L})$ & $5.66 \pm 1.49$ & $5.12 \pm 1.25$ \\
$\mathrm{E}_{2}(\mathrm{pg} / \mathrm{mL})$ & $44.52 \pm 17.94$ & $37.43 \pm 15.31$ \\
$\mathrm{~T}(\mathrm{nmol} / \mathrm{L})$ & $1.13 \pm 0.46$ & $0.91 \pm 0.34$ \\
$\mathrm{AMH}(\mathrm{ng} / \mathrm{mL})$ & $6.44 \pm 0.7^{*}$ & $4.13 \pm 0.88$ \\
Antral follicles & $19.79 \pm 6.05$ & $15.69 \pm 6.93$ \\
hCG $(\mathrm{IU})$ & $4115 \pm 1959^{*}$ & $6076 \pm 1891$ \\
$\mathrm{E}_{2}$ of hCG day $(\mathrm{pg} / \mathrm{mL})$ & $7303 \pm 1778^{* * *}$ & $2206 \pm 673$ \\
Number of retrieved oocytes & $19.75 \pm 9.41^{* *}$ & $10.69 \pm 3.75$ \\
\hline
\end{tabular}

${ }^{*} P<0.05,{ }^{* *} P<0.01,{ }^{* * *} P<0.001$. 
different places and play various roles in different manners. We detected ESR1 and ESR2 in HUVECs, but only ESR2 was highly expressed in HUVECs. Moreover, the KISS1R promoter region contains an ERE and ESR2 is predicted to negatively regulate KISS1R from the sequence structure. The increased KISS1R due to ESR2 reduction demonstrates that $E_{2}$ suppresses the transcription of KISS1R partially by binding to ESR2 in HUVECs. Thus, $E_{2}$ inhibits KISS1R and promotes the increase of VP through ESR2.

Finally, the significantly decreased KISSIR mRNA in granulosa cells of OHSS patients demonstrates its specific role in OHSS onset. However there are also several limitations to our study. We chose human granulosa cells rather than human vascular endothelial cells to demonstrate the role of decreased KISS1R in OHSS because of the limitation in obtaining human endothelial cells. Further studies will be needed, and the sample size should be enlarged to reduce the overlap between the OHSS and control groups.

According to our results, a high level of $E_{2}$ is a risk factor of OHSS. The development of multiple follicles during IVF cycles causes a high level of serum $E_{2}$. Then, $E_{2}$ inhibits KISS1R expression of vascular endothelial cells and ovaries by activating ESR2. The decreased KISS1R in endothelial cells inhibits the suppression of endogenous Kp-10 toVEGFandfacilitates OHSS onset. Exogenous Kp-10 injection promotes the activation of KISS1R and inhibits VEGF. Thus, the reduced VEGF and downstream factors such as NO and VE-cadherin decrease VP and inhibit the incidence of OHSS.

Our study highlights a potential mechanism of OHSS onset and provides a novel possible strategy to prevent OHSS by exogenous Kp-10 injection. In conclusion, Kp-10 prevents the increased VP of OHSS probably by the activation of KISS1R and the inhibition of VEGF.

\section{Declaration of interest}

The authors declare that there is no conflict of interest that could be perceived as prejudicing the impartiality of the research reported.

\section{Funding}

This work was supported in part by grants from the National Natural Science Foundation (81490743 and 81370692), Shanghai Municipal Education Commission-Gaofeng Clinical Medicine (20152510), Shanghai Commission of Science and Technology (17DZ2271100) and doctoral Innovation Found Projects from Shanghai Jiao Tong University School of Medicine (BXJ201619).

\section{Acknowledgments}

The authors are deeply grateful to Xiangwei Hua for kindly providing HUVECs. They especially thank all participants involved in this study.

\section{References}

Abbara A, Jayasena CN, Christopoulos G, Narayanaswamy S, Izzi-Engbeaya C, Nijher GM, Comninos AN, Peters D, Buckley A, Ratnasabapathy $\mathbf{R}$ et al. 2015 Efficacy of Kisspeptin-54 to trigger oocyte maturation in women at high risk of ovarian hyperstimulation syndrome (OHSS) during in vitro fertilization (IVF) therapy. Journal of Clinical Endocrinology and Metabolism 100 3322-3331. (doi:10.1210/ jc.2015-2332)

Aboulghar MA \& Mansour RT 2003 Ovarian hyperstimulation syndrome: classifications and critical analysis of preventive measures. Human Reproduction Update 9 275-289. (doi:10.1093/humupd/dmg018)

Bogin L \& Degani H 2002 Hormonal regulation of VEGF in orthotopic MCF7 human breast cancer. Cancer Research 62 1948-1951.

Braat DD, Schutte JM, Bernardus RE, Mooij TM \& van Leeuwen FE 2010 Maternal death related to IVF in the Netherlands 1984-2008. Human Reproduction 25 1782-1786. (doi:10.1093/humrep/deq080)

Castellano JM, Gaytan M, Roa J, Vigo E, Navarro VM, Bellido C, Dieguez C, Aguilar E, Sanchez-Criado JE, Pellicer A et al. 2006 Expression of KiSS-1 in rat ovary: putative local regulator of ovulation? Endocrinology 147 4852-4862. (doi:10.1210/en.2006-0117)

Cho SG, Yi Z, Pang X, YiT, Wang Y, Luo J, Wu Z, Li D \& Liu M 2009 Kisspeptin-10, a KISS1-derived decapeptide, inhibits tumor angiogenesis by suppressing Sp1-mediated VEGF expression and FAK/Rho GTPase activation. Cancer Research 69 7062-7070. (doi:10.1158/0008-5472.CAN-09-0476)

DeFino MC, Wacker JL, Lyssand JS, Wang EH \& Hague C 2010a Differential regulation of GPR54 transcription by specificity protein-1 and partial estrogen response element in mouse pituitary cells. Biochemical and Biophysical Research Communications 393 603-608. (doi:10.1016/ j.bbrc.2010.02.026)

Delvigne A 2009 Symposium: update on prediction and management of OHSS. Epidemiology of OHSS. Reproductive Biomedicine Online 19 8-13. (doi:10.1016/S1472-6483(10)60040-5)

Delvigne A \& Rozenberg S 2002 Epidemiology and prevention of ovarian hyperstimulation syndrome (OHSS): a review. Human Reproduction Update 8 559-577. (doi:10.1093/humupd/8.6.559)

Farkkila A, Pihlajoki M, Tauriala H, Butzow R, Leminen A, Unkila-Kallio L, Heikinheimo M \& Anttonen M 2011 Serum vascular endothelial growth factor A (VEGF) is elevated in patients with ovarian granulosa cell tumor (GCT), and VEGF inhibition by bevacizumab induces apoptosis in GCT in vitro. Journal of Clinical Endocrinology and Metabolism 96 E1973-E1981. (doi:10.1210/jc.2011-1812)

Fatemi HM, Popovic-Todorovic B, Humaidan P, Kol S, Banker M, Devroey P \& Garcia-Velasco JA 2014 Severe ovarian hyperstimulation syndrome after gonadotropin-releasing hormone $(\mathrm{GnRH})$ agonist trigger and 'freeze-all' approach in GnRH antagonist protocol. Fertility and Sterility 101 1008-1011. (doi:10.1016/j.fertnstert.2014.01.019)

Fernandois D, Na E, Cuevas F, Cruz G, Lara HE \& Paredes AH 2016 Kisspeptin is involved in ovarian follicular development during aging in rats. Journal of Endocrinology 228 161-170. (doi:10.1530/JOE-15-0429)

Ferrero H, Garcia-Pascual CM, Gaytan M, Morales C, Simon C, Gaytan F, Pellicer A \& Gomez R 2014 Dopamine receptor 2 activation inhibits ovarian vascular endothelial growth factor secretion in an ovarian hyperstimulation syndrome (OHSS) animal model: implications for treatment of OHSS with dopamine receptor 2 agonists. Fertility and Sterility 102 1468-1476. (doi:10.1016/j.fertnstert. 2014.07.1240)

Filardo EJ \& Thomas P 2005 GPR30: a seven-transmembrane-spanning estrogen receptor that triggers EGF release. Trends in Endocrinology and Metabolism 16 362-367. (doi:10.1016/j.tem.2005.08.005)

Garcia-Velasco JA \& Pellicer A 2003 New concepts in the understanding of the ovarian hyperstimulation syndrome. Current Opinion in Obstetrics and Gynecology 15 251-256. (doi:10.1097/00001703-200306000-00007)

Garvin S, Nilsson UW, Huss FR, Kratz G \& Dabrosin C 2006 Estradiol increases VEGF in human breast studied by whole-tissue culture. Cell and Tissue Research 325 245-251. (doi:10.1007/s00441-006-0159-7)

Gille H, Kowalski J, Li B, LeCouter J, Moffat B, Zioncheck TF, Pelletier N \& Ferrara N 2001 Analysis of biological effects and signaling properties of Flt-1 (VEGFR-1) and KDR (VEGFR-2). A reassessment using novel receptor-specific vascular endothelial growth factor mutants. Journal of Biological Chemistry 276 3222-3230. (doi:10.1074/jbc. M002016200) 
Golzar F \& Javanmard SH 2015 The effects of kisspeptin-10 on migration and proliferation of endothelial cell. Advanced Biomedical Research 4 41. (doi:10.4103/2277-9175.151250)

Harada M, Peegel H \& Menon KM 2010 Expression of vascular endothelial growth factor A during ligand-induced down-regulation of luteinizing hormone receptor in the ovary. Molecular and Cellular Endocrinology 328 28-33. (doi:10.1016/j.mce.2010.06.015)

He Q, Liang L, Zhang C, Li H, Ge Z, Wang L \& Cui S 2014 Effects of different doses of letrozole on the incidence of early-onset ovarian hyperstimulation syndrome after oocyte retrieval. Systems Biology in Reproductive Medicine 60 355-360. (doi:10.3109/19396368.2014.957879)

Humaidan P, Quartarolo J \& Papanikolaou EG 2010 Preventing ovarian hyperstimulation syndrome: guidance for the clinician. Fertility and Sterility 94 389-400. (doi:10.1016/j.fertnstert.2010.03.028)

Iwase A, Goto M, Harata T, Takigawa S, Nakahara T, Suzuki K, Manabe S \& Kikkawa F 2009 Insulin attenuates the insulin-like growth factor-I (IGF-I)-Akt pathway, not IGF-I-extracellularly regulated kinase pathway, in luteinized granulosa cells with an increase in PTEN. Journal of Clinical Endocrinology and Metabolism 94 2184-2191. (doi:10.1210/ jc.2008-1948)

Jayasena CN, Abbara A, Comninos AN, Nijher GM, Christopoulos G, Narayanaswamy S, Izzi-Engbeaya C, Sridharan M, Mason AJ, Warwick J et al. 2014 Kisspeptin-54 triggers egg maturation in women undergoing in vitro fertilization. Journal of Clinical Investigation $\mathbf{1 2 4}$ 3667-3677. (doi:10.1172/JCl75730)

Kang Q, Chen Y, Zhang X, Yu G, Wan X, Wang J, Bo L \& Zhu K 2016 Heat shock protein A12B protects against sepsis-induced impairment in vascular endothelial permeability. Journal of Surgical Research 202 87-94. (doi:10.1016/j.jss.2015.12.034)

Ling LP, Phoon JW, Lau MS, Chan JK, Viardot-Foucault V, Tan TY, Nadarajah S \& Tan HH 2014 GnRH agonist trigger and ovarian hyperstimulation syndrome: relook at 'freeze-all strategy'. Reproductive Biomedicine Online 29 392-394. (doi:10.1016/j. rbmo.2014.05.012)

MacLean DB, Matsui H, Suri A, Neuwirth R \& Colombel M 2014 Sustained exposure to the investigational Kisspeptin analog, TAK-448, downregulates testosterone into the castration range in healthy males and in patients with prostate cancer: results from two phase 1 studies. Journal of Clinical Endocrinology and Metabolism 99 E1445-E1453. (doi:10.1210/ jc.2013-4236)

Millar RP \& Newton CL 2013 Current and future applications of GnRH, kisspeptin and neurokinin B analogues. Nature Reviews Endocrinology 9 451-466. (doi:10.1038/nrendo.2013.120)

Millar RP, Roseweir AK, Tello JA, Anderson RA, George JT, Morgan K \& Pawson AJ 2010 Kisspeptin antagonists: unraveling the role of kisspeptin in reproductive physiology. Brain Research 1364 81-89. (doi:10.1016/ j.brainres.2010.09.044)

Muir AI, Chamberlain L, Elshourbagy NA, Michalovich D, Moore DJ, Calamari A, Szekeres PG, Sarau HM, Chambers JK, Murdock P et al. 2001 AXOR12, a novel human G protein-coupled receptor, activated by the peptide KiSS-1. Journal of Biological Chemistry 276 28969-28975. (doi:10.1074/jbc.M102743200)

Naredi N, Talwar P \& Sandeep K 2014 VEGF antagonist for the prevention of ovarian hyperstimulation syndrome: current status. Medical Journal Armed Forces India 70 58-63. (doi:10.1016/j.mjafi.2012.03.005)

Neulen J, Yan Z, Raczek S, Weindel K, Keck C, Weich HA, Marme D \& Breckwoldt M 1995 Human chorionic gonadotropin-dependent expression of vascular endothelial growth factor/vascular permeability factor in human granulosa cells: importance in ovarian hyperstimulation syndrome. Journal of Clinical Endocrinology and Metabolism $801967-$ 1971. (doi:10.1210/jcem.80.6.7775647)

Ni Y, Huang Y, Xiao Y, Wu J, Qian F, Grossmann R \& Zhao R 2012 Effects of repeated injection of kisspeptin-10 on the initiation of egglaying in juvenile quail. Animal Reproduction Science 134 203-209. (doi:10.1016/j.anireprosci.2012.08.022)

Novaira HJ, Ng Y, Wolfe A \& Radovick S 2009 Kisspeptin increases GnRH mRNA expression and secretion in $\mathrm{GnRH}$ secreting neuronal cell lines. Molecular and Cellular Endocrinology 311 126-134. (doi:10.1016/j. mce.2009.06.011)
Papanikolaou EG, Pozzobon C, Kolibianakis EM, Camus M, Tournaye H, Fatemi HM, Van Steirteghem A \& Devroey P 2006 Incidence and prediction of ovarian hyperstimulation syndrome in women undergoing gonadotropin-releasing hormone antagonist in vitro fertilization cycles. Fertility and Sterility 85 112-120. (doi:10.1016/j.fertnstert.2005.07.1292)

Peng J, Tang M, Zhang BP, Zhang P, Zhong T, Zong T, Yang B \& Kuang HB 2013 Kisspeptin stimulates progesterone secretion via the Erk1/2 mitogen-activated protein kinase signaling pathway in rat luteal cells. Fertility and Sterility 99 1436-1443. (doi:10.1016/j. fertnstert.2012.12.008)

Pineda R, Garcia-Galiano D, Roseweir A, Romero M, Sanchez-Garrido MA, Ruiz-Pino F, Morgan K, Pinilla L, Millar RP \& Tena-Sempere M 2010 Critical roles of kisspeptins in female puberty and preovulatory gonadotropin surges as revealed by a novel antagonist. Endocrinology 151 722-730. (doi:10.1210/en.2009-0803)

Prossnitz ER \& Barton M 2014 Estrogen biology: new insights into GPER function and clinical opportunities. Molecular and Cellular Endocrinology 389 71-83. (doi:10.1016/j.mce.2014.02.002)

Sahin N, Apaydin N, Toz E, Sivrikoz ON, Genc M, Turan GA, Cengiz H \& Eskicioglu F 2016 Comparison of the effects of letrozole and cabergoline on vascular permeability, ovarian diameter, ovarian tissue VEGF levels, and blood PEDF levels, in a rat model of ovarian hyperstimulation syndrome. Archives of Gynecology and Obstetrics 293 1101-1106. (doi:10.1007/s00404-015-3987-4)

Sebert ME, Lomet D, Said SB, Monget P, Briant C, Scaramuzzi RJ \& Caraty A 2010 Insights into the mechanism by which kisspeptin stimulates a preovulatory LH surge and ovulation in seasonally acyclic ewes: potential role of estradiol. Domestic Animal Endocrinology 38 289-298. (doi:10.1016/j.domaniend.2010.01.001)

Smith JT, Dungan HM, Stoll EA, Gottsch ML, Braun RE, Eacker SM, Clifton DK \& Steiner RA 2005 Differential regulation of KiSS-1 mRNA expression by sex steroids in the brain of the male mouse. Endocrinology 146 2976-2984. (doi:10.1210/en.2005-0323)

Stadtmauer LA, Sarhan A, Duran EH, Beydoun H, Bocca S, Pultz B \& Oehninger S 2011 The impact of a gonadotropin-releasing hormone antagonist on gonadotropin ovulation induction cycles in women with polycystic ovary syndrome: a prospective randomized study. Fertility and Sterility 95 216-220. (doi:10.1016/j.fertnstert.2010.05.023)

Toftager M, Bogstad J, Bryndorf T, LossI K, Roskaer J, Holland T, Praetorius L, Zedeler A, Nilas L \& Pinborg A 2016 Risk of severe ovarian hyperstimulation syndrome in $\mathrm{GnRH}$ antagonist versus $\mathrm{GnRH}$ agonist protocol: RCT including 1050 first IVF/ICSI cycles. Human Reproduction 31 1253-1264. (doi:10.1093/humrep/dew051)

Wang TH, Horng SG, Chang CL, Wu HM, Tsai YJ, Wang HS \& Soong YK 2002 Human chorionic gonadotropin-induced ovarian hyperstimulation syndrome is associated with up-regulation of vascular endothelial growth factor. Journal of Clinical Endocrinology and Metabolism 87 3300-3308. (doi:10.1210/jcem.87.7.8651)

Wang L, Chen Q, Li G \& Ke D 2015 Ghrelin ameliorates impaired angiogenesis of ischemic myocardium through GHSR1a-mediated AMPK/eNOS signal pathway in diabetic rats. Peptides 73 77-87. (doi:10.1016/j.peptides.2015.09.004)

Xiao Y, Ni Y, Huang Y, Wu J, Grossmann R \& Zhao R 2011 Effects of kisspeptin-10 on progesterone secretion in cultured chicken ovarian granulosa cells from preovulatory (F1-F3) follicles. Peptides 32 2091-2097. (doi:10.1016/j.peptides.2011.09.001)

Yan Z, Weich HA, Bernart W, Breckwoldt M \& Neulen J 1993 Vascular endothelial growth factor (VEGF) messenger ribonucleic acid (mRNA) expression in luteinized human granulosa cells in vitro. Journal of Clinical Endocrinology and Metabolism 77 1723-1725. (doi:10.1210/ jcem.77.6.8263163)

Received 4 May 2017

First decision 5 June 2017

Revised manuscript received 8 June 2017

Accepted 4 July 2017 